matory mediators such as prostaglandins may play in food intolerance underscores the folly of attributing all food intolerance to classical immunological mechanisms. Treatment by exclusion diets is a demanding occupation for skilled dietitians, and many inconsistencies in published reports may well be attributable to the varying zeal with which exclusion diets are pursued. Dr P Hall-Smith (Brighton Health Authority) made the constructive suggestion that proper instruction should be available for dietitians wishing to undertake this task. As yet there is little evidence that sodium cromoglycate has reduced the importance of dietary measures, and only one study by Professor Louisa Businco (University of Rome) provided any controlled data in a study of atopic eczema that this drug is helpful in common disorders allegedly attributable to food intolerance.

A M DENMAN

Consultant Physician,

Connective Tissue Disease Research Group,

Clinical Research Centre,

Harrow HAl 3UJ

\section{Clinical biochemistry nearer the patient}

Despite its expansion in the past two decades clinical biochemistry has undergone little conceptual change since it first became an indispensable part of hospital practice some 60 years ago. Now, however, it is on the brink ${ }^{1-5}$ of a revolution far more reaching in effect than the purely quantitative one arising from the introduction of automation in the early 1960s. The new factor-comparable in importance to the introduction of the stethoscope by Laennec in the nineteenth century-is our ability to perform tests much nearer to the patient than was hitherto possible. Analytical procedures previously able to be performed only in custom built laboratories staffed by highly trained technicians and scientists can now be carried out by relatively unskilled staff in the clinic or in the ward without loss of precision or accuracy. ${ }^{\circ}$

The technical background to this shange is a series of advances in the construction of ion specific and enzyme electrodes, in solid phase chemistry, electronics, non-invasive "chemical" probes, microprocessors, and, above ail, in the miniaturisation of apparatus. This change from the old to the new way of doing clinical chemistry will not be achieved painlessly or without a struggle. Laboratory workers will see themselves threatened by an apparent down grading of their hard learnt skills, and clinicians will need to rethink the way they request pathological tests and indeed their whole clinical behaviour.

Once insulin became available in 1922 patients suffering from diabetes mellitus could no longer reasonably be treated without ready access to blood glucose measurements-not primarily for diagnostic purposes but as a guide to dosage and monitoring treatment. This early but key monitoring function of analytical chemistry as a guide to the benefit, or otherwise, of treatment accounts for at least one third of all laboratory requests in clinical chemistry ${ }^{7}$ and is growing in importance with the trend towards tailoring drug treatment to the individual. ${ }^{8}$ It has, however, been largely overshadowed by the more dramatic use of clinical chemistry as an aid to diagnosis and its largely abortive application to screening for early or unsuspected diseases. Indeed, as much as anything, belief in screening tests was responsible for the introduction into laboratories of expensive multichannel instruments capable of producing large numbers of mainly irrelevant, often uninterpretable, and occasionally misleading results ${ }^{9-12}$ - though their saving grace was a commendably high standard of analytical precision and accuracy.

Since the numbers of tests performed, their precision, and their accuracy are all easy to quantify, these aspects of laboratory performance (rather than the clinical value and relevance of the service provided) have tended to become the yardstick against which quality and cost effectiveness have been judged. Similarly the status of laboratory heads and technicians has grown in direct proportion to the size and complexity of their instruments, which could reasonably be housed only in large central laboratories often remote from the patients they served. This, in turn, has demanded the introduction of elaborate systems for the collection, processing, documentation, and dissemination of information-which for many tests cost more than the actual analysis ${ }^{13}$ and, despite computerisation, still depend heavily on human factors, not the least of which is the sense of participation. Indeed, human factors account for most of the $1-2 \%$ of all results dispatched from laboratories that are hopelessly wrong, and since these are mostly due to errors in clerking, labelling, or transcription outside the analytical area they may often be completely beyond the control of the laboratory director.

Over the years disillusionment has grown with the cost effectiveness and clinical usefulness of many clinical chemical procedures as presently performed. ${ }^{14-17}$ The only remedy seemed to be better education. ${ }^{18-24}$ All this will be changed, however, with the gradual introduction of technically advanced but cheap and portable analytical systems suitable for small laboratories, hospital outpatient clinics, intensive treatment and special care units, ward side rooms, general practitioners' surgeries, and even patients themselves. These new systems are within the technical competence of virtually any literate and sufficiently well motivated person, ${ }^{522} 23$ and their advent demands an urgent reappraisal of the part played by clinical laboratories in modern medical practice.

Apart from purely technical considerations, such as the specificity, accuracy, and reliability of the apparatus to be used, several other questions need to be answered before clinical chemistry becomes established nearer the patient: these include the question of who should initiate, carry out, interpiet, and assume legal responsibility for tests performed outside the laboratory. Special problems are posed by screening tests in those rare cases where they can be scientifically and ethically justified ${ }^{24}$ and by some essential procedures which are required only rarely and for which reliable "black box" technology is not and is unlikely to become available. Possibly as common tests become devolved to clinics and wards certain specialist procedures will become concentrated in fewer institutions-though not necessarily all in the same place. This should ensure the maintenance of high analytical and interpretative skills required to make them clinically useful.

Some of the benefits that may be expected from decentralisation are already apparent. Self calibrating blood gas analysers capable of being operated by comparatively unskilled medical staff have improved the quality of clinical care provided by intensive care units; the effects of blood glucose analysers on the management of diabetes and of non-invasive percutaneous reflectance bilirubinometers on neonatology represent just two tips of the iceberg. The day cannot be far 
away when many, if not most, of the 20-30 most popular chemical tests performed in hospital clinical laboratories (and accounting for around $80 \%$ of their current analytical workload) will be carried out with greater discrimination and in smaller numbers closer to the patient-sometimes by clinicians themselves as part of their physical examination. In these circumstances clinical chemical tests would be no different in concept from measurement of the blood pressure or examination of the fundus with an ophthalmoscope. This would have the advantage of immediacy and relevance as well as providing the clinician with the opportunity to investigate further, by direct observation or questioning, any discrepancy between the expected and observed result. Such discrepancies may arise from inadvertent withdrawal of blood from an arm into which an intravenous infusion is being given, from interference with an analytical result by a drug whose administration would probably not be mentioned on the traditional laboratory request form, or any number of other factors that contrive to make random analytical results, devoid of background information, unintelligible and uninterpretable like a misplaced piece of jigsaw. A further advantage of decentralisation would be a reduction in the role of the middle men concerned with the collection, transportation, and documentation of specimens who add nothing but expense, delay, and the risk of misdesignation to the value of analytical results received from geographically isolated laboratories. Decentralisation would not, however, preclude clinicians seeking advice from clinical biochemists and chemical pathologists, who, relieved cf the necessity of serving as laboratory managers, could develop and exploit their analytical skills and special knowledge of biochemistry and pathologic physiology.

An international conference to review current practice and discuss the likely impact of performing clinical biochemistry nearer the patient has been organised at the University of Surrey on 4-6 September this year. Particulars may be obtained from me at the address given below.

\section{VINCENT MARKS}

Professor of Clinical Biochemistry,

University of Surrey,

Guildford GU2 5XH

I Rinsler MG. Chemical-pathology services. Lancet 1977 ; :946-7.

2 Mitchell FL. The trend towards devolution in clinical chemistry. Fournal of Automatic Chemistry 1979;1:179-81.

${ }^{3}$ Wiener K. Pathology measurements closer to the patient? $\mathcal{F}$ Clin Pathol $1980 ; 33: 857-63$.

+ Anderson JR, Lindsell WD, Mitchell FM. Chemical pathology on the ward. Lancet $1981 ; \mathrm{i}: 487$.

${ }^{5}$ Watson D. Analytical investigations closer to the patient. $\mathrm{Br} \mathrm{Med} f$ $1980 ; 281: 31-5$

${ }^{6}$ Minty BD, Barrett AM. Accuracy of an automated blood-gas analyser operated by untrained staff. Br F Anaesth 1978;50:1031-9.

Wertman BG, Sostrin SV, Pavlova Z, Lundberg GD. Why do physicians order laboratory tests? A study of laboratory test requests and use patterns. F $A M A$ 1980;243:2080-2.

"Richens A, Marks V, eds. Therapeutic drug monitoring. Edinburgh Churchill Livingstone, 1981.

9 D'Souza MF. The value of screening and health surveillance to employment. $7 R$ Coll Physicians Lond 1978;12:230-9.

${ }^{10}$ Anonymous. The value of diagnostic tests. Lancet $1979 ; \mathrm{i}: 809-10$

1 Marks V. The choice between discretionary and profile testing. In Price CP, Spencer K, eds. Centrifugal analysers in clinical chemistry. Eastbourne: Praeger, 1980:259-70.

12. Griner PF, Glaser RJ. Misuse of laboratory tests and diagnostic procedures. $N$ Engl f Med 1982;307:1336-9.

13 Stilwell JA. Costs of a clinical chemistry laboratory. $\mathcal{F}$ Clin Pathol 1981 34:589-94.

${ }^{14}$ Hampton JR, Harrison MJG, Mitchell JRA, Prichard JS, Seymour C. Relative contributions of history-taking, physical examination, and laboratory investigation to diagnosis and management of medical outpatients. Br Med F 1975;ii:486-9.
${ }^{15}$ Sandler G. Costs of unnecessary tests. Br Med 71979 ;ii :21-4.

${ }^{6}$ Fineberg HV. Clinical chemistries: the high cost of low-cost diagnostic tests. In: Altman SH, Blendon R, eds. Medical technology: the culprit behind health care cost. Washington, DC: Government Printing Office, 1979:144-65.

${ }_{17}$ Mitchell JRA, Wilcox RG, Hampton JR. Necessary tests or ritual dances ? Lancet 1982; ;i:990.

18 Cassells W, Schoenberger A, Graboys TB. Interpretation by physicians of clinical laboratory results. $N$ Engl F Med 1978;299:999-1001.

19 Young DW. An aid to reducing unnecessary investigations. $\mathrm{Br}$ Med $\mathcal{f}$ $1980 ; 281: 1610-1$

${ }^{20}$ Martin AR, Wolf MA, Thibodeau LA, Dzau V, Braunwald E. A trial of two strategies to modify the test-ordering behavior of medical residents. $N$ Engl f Med 1980;303:1330-6.

${ }^{21}$ Anonymous. Reducing tests. Lancet 1981;i:539-40.

${ }^{22}$ Mitchell FL. Pathology measurements nearer the patient. Medical Laboratory World 1982 November:8-14.

${ }^{23}$ Thomas L, Pilschke W, Storz G. Evaluation of a quantitative solid phase reagent system for determination of blood analytes. Ann Clin Biochem 1982;19:214-23.

${ }^{24}$ Gitzelmann R. Why we should not screen our newborns for cystic fibrosis. Helv Paediatr Acta 1981 ;36 :493-4.

\section{Adult respiratory distress syndrome}

Despite the advances in treatment more than half of the patients who develop the adult respiratory distress syndrome will die-a figure unchanged in the last 10 years. Thus recent reviews of the syndrome make depressing reáding. ${ }^{1-4}$

The adult respiratory distress syndrome comprises pulmonary oedema of non-cardiac origin, with destruction of pulmonary architecture; it is associated with a variety of conditions. The initial insult, which may directly damage the lungs, includes trauma, infection, aspiration, fat embolism, or the inhalation of toxic agents including high concentrations of oxygen. Often, however, there is no initial pulmonary damage, with a history of trauma to other parts of the body, burns, shock, sepsis, or pancreatitis. There is usually a latent period of 12-48 hours before respiratory symptoms occur. The patient (who has neither pre-existing pulmonary disease nor left ventricular failure) becomes hypoxaemic and lung compliance is reduced. Chest radiography shows bilateral diffuse infiltration. In the past the syndrome was probably recognised as "wet lung" in battle casualties or "congestive atelectasis," but not until 1967 was the current term adult respiratory distress syndrome adopted. ${ }^{5}$ Advances in artificial ventilation produced an initial reduction in mortality, which has been maintained but not improved on. Patients now seldom die of hypoxaemia or hypercapnia but of "multiorgan failure" after a period of intensive treatment. The label adult respiratory distress syndrome emphasises the respiratory element of the syndrome but conceals the fact that there is extensive damage throughout the body.

The process begins when tissue damage stimulates the autonomic nervous system, releases vasoactive substances, precipitates complement activation, and produces abnormalities of the clotting cascade. ${ }^{6}$ The humoral and autonomic responses to injury or the changes in blood pressure or volume lead to maldistribution of blood in the pulmonary vasculature. Complement activation causes aggregation of neutrophils, which lodge in the pulmonary capillary bed. There they release superoxide radicals, which damage endothelium, and proteases, which damage the structural components of the lung-collagen, elastin, and fibronectin. Superoxide radicals also decrease the activity of potentially protective antiproteases present in the lung. Plugs of fibrin and platelet 